\title{
Path following of unmanned surface vessel under effect of position measurement noise
}

\author{
Tran Ngoc Huy ${ }^{*}$, Pham Nguyen Nhut Thanh
}

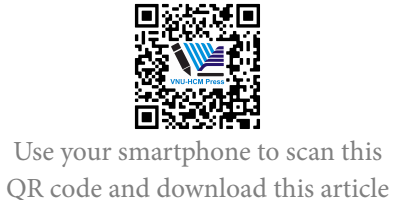

Ho Chi Minh city University of

Technology, VNU-HCM

Correspondence

Tran Ngoc Huy, Ho Chi Minh city University of Technology, VNU-HCM

Email: tnhuy@hcmut.edu.vn

History

- Received: 15-1-2018

- Accepted: 19-12-2018

- Published: xx-12-2019

DOI :10.32508/stdjet.v3iSI1.721

\section{Check for updates}

Copyright

( ) VNU-HCM Press. This is an openaccess article distributed under the terms of the Creative Commons Attribution 4.0 International license.

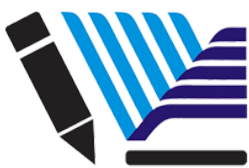

VNU-HCM Press

\begin{abstract}
A manipulation system for unmanned surface vessels (USVs) as well as other unmanned vehicles and autonomous vehicles are commonly built up by three vital components which are guidance system, navigation system and control system, regardless of the mechanical aspects. In which, the navigation system will first use sensors to measure and estimate parameters, then feedback to the guidance system and the control system as input data. Based on those data and assignments from user, the guidance system calculates and outputs reference data for the control system. The control system will drive the vessel according to the reference data from guidance system to achieve those assignments. However, the process of measuring and estimating, in fact, is always affected by disturbances which cause input error for guidance system. Consequently, the reference data provided by the guidance system will be skewed and confused the control system, thereby reducing the quality of control and may cause instability for the whole system. This paper examines the problem of controlling an unmanned surface vessel following straight paths created by the waypoints which given by user. To solve the path-following for straight line problem, the paper will build a guidance system using the Line of Sight (LOS) method with lookahead distance and design a controller using Backstepping algorithm. In addition, this paper will also study, analyze and propose a method to reduce the influence of position measurement noise to the process of calculating the reference data of guidance system. Thereby, the quality of the built system will be guaranteed when operating under the influence of measurement noise. The results of the proposed method will be shown through simulation on MATLAB/SIMULINK software. These simulation results will demonstrate the effectiveness and feasibility of the proposed method.

Key words: USV, Path-Following, Line of sight (LOS), Backstepping, Sliding mode
\end{abstract}

\section{INTRODUCTION}

In the age of technological explosion, automatic, unmanned and other intelligent devices are more and more widely researched and developed at a fast pace and easily applied to practice. This has created a lot of premises for people to explore the world and find new resources, especially the water environment which covers more than $70 \%$ of the earth's surface. Hence, we have to use robots in those situations where humans cannot discover by themselves. As a result, autonomous or unmanned devices working on the water's surface and underwater are being considered and developed strongly.

The first unmanned surface vessel (USV) Autocat of MIT published in 2000 for the hydrographic survey at Boston Harbor had begun a robust development process for many unmanned surface vehicles which used to survey the water environment, such as USV SESAMO of Italy, USV ROAZ of Portugal, USV Springer of the University of Plymouth. Besides, there were also many USVs that had been studied for military purposes such as USV KATANA of Israel, USV Protector Rafael of the United States. In the field of civil purposes, there was the autonomous surface vessel (ASV) C-Worker 12P used for transport or ASV Waste Shark used to clean up the trash on rivers, lakes, etc. Such applications of those types of unmanned surface vessel are described in ${ }^{1,2}$, and ${ }^{3}$. At the same time, underwater vehicles have also grown at a dramatic rate. People nowadays tend to incorporate USV, autonomous underwater vehicle (AUV), remotely operated vehicle (ROV) into a more complete system for various purposes. Some applications, as well as underwater vehicles, are described in ${ }^{4-7}$. In this paper, we will consider the problem of constructing a system for an unmanned surface vessel so that it can follow a straight path formed by the given waypoints. In addition, we will also consider the effect of position measurement noise on the system. A USV as well as any other unmanned vehicles, in order to follow a trajectory, cannot lack the guidance and control system as described in ${ }^{8}$. Hence, this paper will present how to build a guidance system us- 
ing LOS method to calculate desired heading angle and design controllers to track those computed results from the guidance and satisfy the speed assignment in the movement. Furthermore, this paper proposes a method to reduce the effect of position measurement noise on the quality control of the mentioned system.

\section{VESSEL MODEL}

Mathematical models of the vessel can be built in a general way. However, to understand the dynamics and properties of the force acting on the vessel and construct a suitable controller, we need to take the thruster configuration into consideration. Typically, USVs that perform research or civil functions are commonly have two hull form because of high stability such as the USV ROAZ and USV Springer, also serve the military often have a single body because of high speed and mobility like USV KATANA or USV Rafael. In this paper, we consider the engine layout as well as the characteristics of the control force with the two hull model.

Define the three DOF $\eta=[x, y, \psi]^{T}$ indicate position $(x, y)$ and heading $(\psi)$ of the vessel in an earthfixed inertial frame $\{\mathrm{e}\}$, and $v=[u, v, r]^{T}$ be the corresponding linear velocities called surge $(u)$, sway $(v)$ and angular rate $(r)$ called yaw in the body-fixed frame $\{b\}$ in Figure 1. According to ${ }^{9}$ the dynamic model of the vessel is

$\left\{\begin{array}{l}\dot{\eta}=R(\psi) v \\ M \dot{v}+C(v) v+D(v) v=\tau\end{array}\right.$

where $R($.$) is the three DOF rotation matrix, M$ is the system inertia matrix, $C(v)$ is a skew-symmetric matrix of Coriolis and centripetal terms, $D(v)$ is the damping matrix. All were sequentially calculated by following equations:

$R(\psi)=\left(\begin{array}{ccc}\cos (\psi) & -\sin (\psi) & 0 \\ \sin (\psi) & \cos (\psi) & 0 \\ 0 & 0 & 1\end{array}\right)$

$M \quad=\left(\begin{array}{ccc}m_{11} & 0 & 0 \\ 0 & m_{22} & m_{23} \\ 0 & m_{32} & m_{33}\end{array}\right)$

$\left(\begin{array}{ccc}m-X_{\dot{u}} & 0 & 0 \\ 0 & m-Y_{i} & m x_{G}-Y_{i} \\ 0 & m x_{G}-N_{i} & I_{Z}-N_{i}\end{array}\right)$

$C(v)=\left(\begin{array}{ccc}0 & 0 & c_{13} \\ 0 & 0 & c_{23} \\ -c_{13} & -c_{23} & 0\end{array}\right)$

with $c_{13}=-\left(m-Y_{\dot{V}}\right) v-\left(m x_{G}-Y_{\dot{r}}\right) r$ and $c_{23}=(m-$ $X_{\dot{u}) u}$.

$D(v)=\left(\begin{array}{ccc}d_{11} & 0 & 0 \\ 0 & d_{22} & d_{23} \\ 0 & d_{32} & d_{33}\end{array}\right)$

$$
\begin{aligned}
& d_{11}=-X_{u}-X_{|u| u}|U| ; d_{22}=-Y_{v}-Y_{|v| v}|v|-Y_{|r| v}|r| ; \\
& d_{23}=-Y_{r}-Y_{|v| r}|v|-Y_{|r| r \mid}|r| \text {; } \\
& \text { with } \quad \begin{aligned}
d_{23} & =-Y_{r}-Y_{|v| r \mid}|v|-Y_{|r| r \mid} \mid \\
d_{32} & =-N_{v}-N_{|v| v}|v|-N_{|r| v}|r| ;
\end{aligned} \\
& d_{33}=-N_{r}-N_{|v| r}|v|-N_{|r| r}|r| \text {. }
\end{aligned}
$$

where $x_{G}$ is the distance from the center of gravity of vessel to the origin of the body-fixed frame $\{b\}$. The coefficients $\left\{X_{(.)}, Y_{(.)}, N_{(.)}\right\}$are hydrodynamic parameters according to the notation in ${ }^{10}$ and $\tau=$ $\left[\tau_{1}, \tau_{2}, \tau_{3}\right]^{\tau}$ is the control input. Equation (1) can be expressed as:

$$
\left\{\begin{array}{c}
\dot{x}=u \cos (\psi)-v \sin (\psi) \\
\dot{y}=u \sin (\psi)-v \cos (\psi) \\
\dot{\psi}=r \\
m_{11} \dot{u}=\tau_{1}-c_{13} r-d_{11} u \\
m_{22} \dot{v}+m_{23} \dot{r}=-c_{23} r-d_{22} v-d_{23} r \\
m_{32} \dot{v}+m_{33} \dot{r}=\tau_{3}+c_{13} u+c_{23} v-d_{32} v-d_{33} r
\end{array}\right.
$$

The thruster configuration of USV is shown in Figure 2 and the force and torque are related to the control input $\tau$ through the equation:

$\tau=\left[\begin{array}{l}\tau_{1} \\ \tau_{2} \\ \tau_{3}\end{array}\right]=\left[\begin{array}{cccc}1 & 1 & 0 & 0 \\ 0 & 0 & 1 & 1 \\ L_{y 1} & -L_{x 1} & L_{x 1} & L_{x 2}\end{array}\right]\left[\begin{array}{l}F_{1} \\ F_{2} \\ F_{3} \\ F_{4}\end{array}\right]$

From (7) we can choose the force $\mathrm{F}_{3}=-\mathrm{F}_{4}$ so

$\tau=\left[\tau_{1}, 0, \tau_{3}\right]^{\tau}$

\section{METHODOLOGY OF GUIDANCE}

This paper considers the path following problem for unmanned vehicles, in which the path is formed by connecting the given waypoints. To solve this problem there are many different methods, however, for marine craft Line of Sight (LOS) is the popular method and LOS has proved very effective because of the way it works similar to the helmsman, which will typically steer the vessel towards a point lying a constant distance, called the look-ahead distance, ahead of the vessel, along the desired path ${ }^{11}$. Furthermore LOS guidance algorithms allow the vehicle at any initial position outside the desired path to converge and stay on the path. So this paper choose LOS method to design guidance.

\section{Cross-track Error}

Suppose that USV needs to be converged on the path that are connected by two way-points $w p(k)$ and $\mathrm{wp}(k+1)$ as in Figure 3, when the angle $\alpha_{p}$ can be determined by formula:

$\alpha_{p}=a \tan 2\left(y_{k+1}-y_{k}, x_{k+1}-x_{k}\right)$

For the USV located at $(x, y)$, the along-track $\left(x_{e}\right)$ and cross-track $\left(y_{e}\right)$ are defined by:

$\left[\begin{array}{l}x_{e} \\ y_{e}\end{array}\right]=\left[\begin{array}{cc}\cos _{\left(\alpha_{P}\right)} & -\sin _{\left(\alpha_{P}\right)} \\ \sin _{\left(\alpha_{P}\right)} & \cos _{\left(\alpha_{P}\right)}\end{array}\right]^{T}\left[\begin{array}{l}x-x_{k} \\ y-y_{k}\end{array}\right]$ 


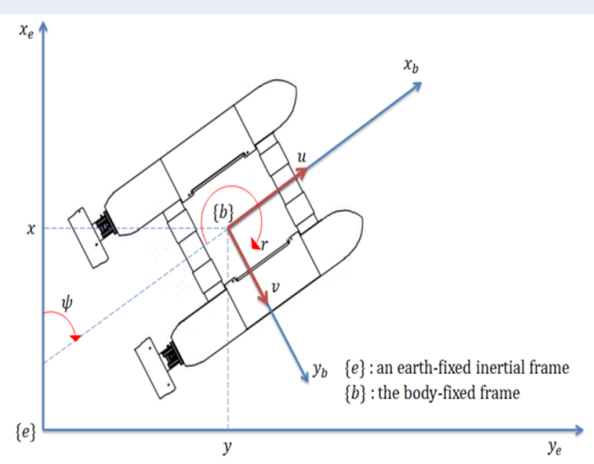

Figure 1: Reference frame.

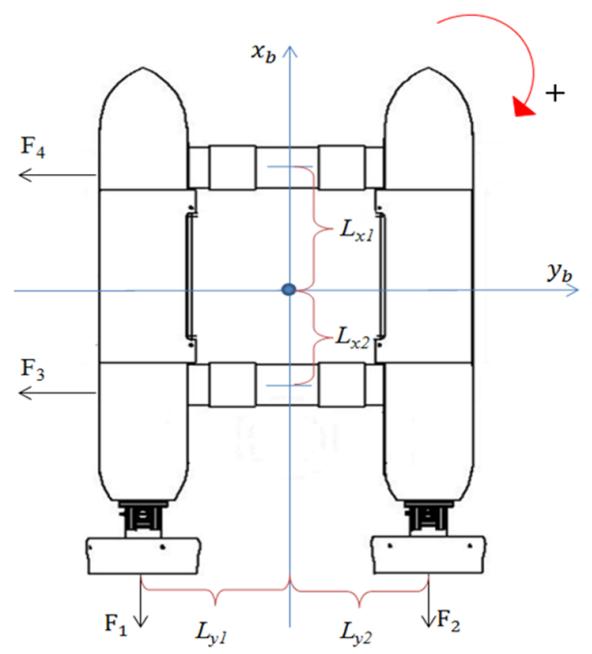

Figure 2: Thruster configuration.

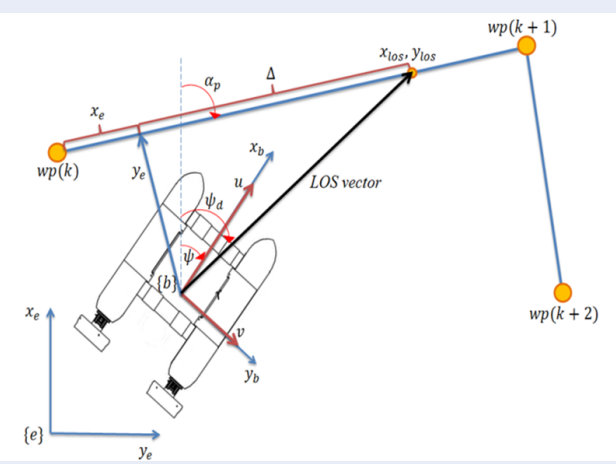

Figure 3: LOS guidance geometry. 
where $\left(x_{k}, y_{k}\right)$ is the coordinates of $\mathrm{wp}(k)$ in an earthfixed inertial frame $(k=1 \ldots \mathrm{N})$.

Expanding (10) we get:

$$
\begin{aligned}
& x_{e}=\left(x-x_{k}\right) \cos \left(\alpha_{P}\right)+\left(y-y_{k}\right) \sin \left(\alpha_{P}\right) \\
& y_{e}=-\left(x-x_{k}\right) \sin \left(\alpha_{P}\right)+\left(y-y_{k}\right) \cos \left(\alpha_{P}\right)
\end{aligned}
$$

The goal is making the vessel converge and stay on the path can be expressed by the equation below:

$\lim _{t \rightarrow \infty} y_{e}(t)=0$

\section{Guidance law}

With the application of path following for the surface vehicles, the LOS vector is considered as a vector with tail at the origin of body-fixed frame and head is located at a point $\left(x_{\text {los }}, y_{\text {los }}\right)$ on the tangent line connecting two way-points $\mathrm{wp}(k)$ and $\mathrm{wp}(k+1)$. The distance between $\left(x_{\text {los }}, y_{\text {los }}\right)$ and projection of vehicle on the tangent line is called lookahead distance and denoted by $\Delta$ as illustrated in Figure 3. The lookahead distance is selected in the common way as a constant and it is usually determined in experimental. In this paper, the lookahead distance will be chosen as a function to reduce the effect of measurement noise affecting the system.

With the LOS vector defined above, the desired heading can be determined by formula:

$\psi_{d}=\alpha_{p}+\arctan \left(\frac{-y_{e}}{\triangle}\right)$

\section{Lookahead distance $\Delta$}

From (12), we can see the value of the desired heading $\psi_{d}$ changes when $\mathrm{y}_{e}$ changes. Besides that $\mathrm{y}_{e}$ changes when the coordinates $(x, y)$ change, this is denoted in (10). Therefore, if the coordinates $(x, y)$ are affected by the measurement noise, it will directly affect the value of desired heading angle so reduce the quality of the control.

This paper presents a method for reducing the effect of measuring noise on the quality of control by choosing the lookahead distance $\Delta$ (also known as Delta) as a function of $\mathrm{y}_{e}$.

Denote the measurement noise of coordinates $(x, y)$ is $(\Delta \mathrm{x}, \Delta \mathrm{y})$ and assume that these values are bounded, where $|\triangle x| \leq M,|\triangle y| \leq M$.

Denote the value difference of $\mathrm{y}_{e}$ with and without noise is $\widetilde{y}_{e}$. We have:

$\tilde{y}_{e}=-\Delta x \sin \left(\alpha_{p}\right)+\Delta y \cos \left(\alpha_{p}\right)$

The boundary value of $\widetilde{y}_{e}$

$\left|\widetilde{y}_{e}\right| \leq|\triangle x|\left|\sin \left(\alpha_{p}\right)\right|+|\triangle y|\left|\cos \left(\alpha_{p}\right)\right| \leq$ $M\left(\left|\sin \left(\alpha_{p}\right)\right|+\left|\cos \left(\alpha_{p}\right)\right| \leq \sqrt{2} M\right.$

Similarly, denote the value difference of $\psi_{d}$ with and without noise is $\vec{\psi}_{d}$. We get:

$\vec{\psi}_{d}=\arctan \left(\frac{y_{e}+\widetilde{y_{e}}}{\triangle}\right)-\arctan \left(\frac{y_{e}}{\triangle}\right)$
The target is find the function $\Delta\left(y_{e}\right)$ to minimize $\left|\Psi_{d}\right|$ as small as possible. To do that, firstly we find the maximum value of $\left|\Psi_{d}\right|$. Let $\left|\square_{d}\right|$ is a function of $\widetilde{y}_{e}$ or $⿱_{d}=f\left(\widetilde{y}_{e}\right)$. The time derivative of $f\left(\widetilde{y}_{e}\right)$ is

$f^{\prime}\left(\tilde{y}_{e}\right)=\frac{1}{1+\left(\frac{y_{e}+\tilde{y}_{e}}{\triangle}\right)^{2}} \cdot \frac{1}{\triangle}>0$

Implied $f(M) \geq \vec{\psi}_{d} \geq f(-M)$. Noted that $\mathrm{f}(0)=0$ so $\mathrm{f}(\mathrm{M})>0>\mathrm{f}(-\mathrm{M})$. We have:

$$
\begin{aligned}
& \tan (|f(M)|)-\tan (|f(-M)|) \\
&=\tan (|f(M)|)-\tan (-f(-M)) \\
&=\frac{y_{e}+M}{\triangle}-\frac{y_{e}}{\triangle} \\
&=\frac{\Delta}{1+\frac{y_{e}}{\triangle}\left(\frac{y_{e}+M}{\triangle}\right)}-\frac{\frac{y_{e}}{\triangle}-\frac{y_{e}-M}{\triangle}}{1+\frac{y_{e}}{\triangle}\left(\frac{y_{e}-M}{\triangle}\right)} \\
&= \frac{-2 y_{e} M_{2} \triangle}{\left[\triangle^{2}+y_{e}\right]\left(y_{e}+M\right)\left[\triangle^{2}+y_{e}\left(y_{e}-M\right)\right]}
\end{aligned}
$$

And $\tan ($.$) is a covariance function so:$

$\operatorname{Max}\left|\psi_{d}\right|=\left\{\begin{array}{l}f(M), y_{e} \leq 0 \\ -f(-M), y_{e}>0\end{array}\right.$

Expanding (16) we can get:

$\operatorname{Max}\left|\psi_{d}\right|=\arctan \left(\frac{\left|y_{e}\right|}{\triangle}\right)-\arctan \left(\frac{\left|y_{e}\right|-M}{\triangle}\right)$

Next, we consider Max $\left|q_{d}\right|=g(\triangle)$ with $\Delta>0$ and find the value of $\Delta$ so that $g(\Delta)$ is minimum. Unluckily, those value does not exist. Hence, we will find the value of $\Delta$ so that $\operatorname{Max}\left|\psi_{d}\right|=P$ with $\mathrm{P}$ is a value given by user. $P$ can be interpreted as the maximum allowed angular error. We have:

$$
\begin{aligned}
& \operatorname{Max}\left|\psi_{d}\right|=P
\end{aligned}
$$

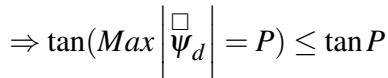

$$
\begin{aligned}
& \Leftrightarrow \frac{M \triangle}{\triangle^{2}+\left|y_{e}\right|\left(\left|y_{e}\right|-M\right)} \leq \tan P
\end{aligned}
$$

Solve (18) we get:

$$
\begin{aligned}
& \left\{\begin{array}{c}
\triangle \\
\begin{array}{c}
\triangle \\
\triangle
\end{array} \triangle_{2}, \triangle_{1},\left|y_{e}\right| \leq M \\
\forall \triangle_{1}, M<\left|y_{e}\right|>y_{z} \mid \leq y_{z}
\end{array}\right. \\
& \text { with } \\
& \left\{\begin{array}{c}
\triangle_{1}=\frac{M}{\tan P}+\sqrt{\left(\frac{M}{\tan P}\right)^{2}-4\left|y_{e}\right|\left(\left|y_{e}\right|-M\right)} \\
\triangle_{2}=\frac{M}{\tan P}-\sqrt{\left(\frac{M}{\tan P}\right)^{2}-4\left|y_{e}\right|\left(\left|y_{e}\right|-M\right)} \\
y_{z}=\frac{M}{2}\left(1+\frac{1}{\sin P}\right)
\end{array}\right.
\end{aligned}
$$

Because we want to keep the value of the desired heading is a continuous function by time so $\Delta$ must be countinous too. In order to reduce the complexity when calculating $\Delta$, we choose

$$
\left\{\begin{array}{c}
\triangle \geq \triangle_{1},\left|y_{e}\right| \leq M \\
\triangle \geq \triangle_{1}, M<\left|y_{e}\right| \leq y_{z} \\
\forall \triangle,\left|y_{e}\right|>y_{z}
\end{array}\right.
$$




\section{METHODOLOGY OF CONTROLLER}

The desired heading angle will be provided by guidance and the speed assignment will be given by user, so we can divide the problem into two control problems include speed control and heading control ${ }^{12,13}$. Where control algorithm applied in speed controller is Sliding mode and heading controller is Backstepping Sliding Mode (BSM).

\section{Speed controller}

Because property of control input which have, we can approximate $U=\sqrt{u^{2}+v^{2}} \approx u$. Suppose the desired velocity is $\mathrm{u}_{d}$, define the speed error $e_{u}=u-u_{d}$. From (6), the time derivative of speed error can be determined:

$\dot{e}_{u}=\dot{u}-\dot{u}_{d}=\left(\tau_{1}-c_{13} r-d_{11} u\right) / m_{11}-\dot{u}_{d}$

Select the sliding surface $s_{u}=e_{u}$ and define the control Lyapunov function $V_{u}=s_{u}^{2} / 2>0$ whose time derivative is

$\dot{V}_{u}=s_{u} \dot{s}_{u}=s_{u}\left[\left(\tau_{1}-c_{13} r-d_{11} u / m_{11}-\dot{u}_{d}\right)\right]$

Select the control law

$\tau_{1=} c_{13} r+d_{11} u+m_{11}\left(\dot{u}_{d}-K_{u} \operatorname{sat}\left(s_{u}\right)\right)$

where $K_{u}$ is positive constant. From (23) and (24) we get $\dot{V}_{u}=-K_{u}$ sat $\left(s_{u}\right) s_{u}<0$. Follow Lyapunov theory $s_{u} \rightarrow 0$ or $e_{u} \rightarrow 0$.

\section{Heading controller}

We will use Backstepping Sliding mode for design heading controller. From (6):

$$
\begin{aligned}
\dot{r}= & f_{\dot{r}(u, v, r)+g_{i \tau_{3}} \text { where }} \\
& a_{\dot{r}(u, v, r)=\frac{1}{m_{22} m_{33}-m_{32} m_{23}}\left[m_{22} c_{13} u\right.} \\
& +c_{23}\left(m_{22} v+m_{32} r\right) \\
& +v\left(d_{22} m_{32}-d_{32} m_{22}\right) \\
+ & \left.r\left(d_{23} m_{32}-d_{33} m_{22}\right)\right] \\
b_{r}= & \frac{m_{22}}{m_{22} m_{33}-m_{32} m_{23}}
\end{aligned}
$$

Define the heading error $e_{\psi}=\psi-\psi_{d}$. The first derivative are $\dot{e}_{\psi}=r-\dot{\psi}_{d}$

Step 1:

Define the first control Lyapunov function (CLF) as $V_{1}=e_{\psi}^{2} / 2>0$

whose time derivative is

$\dot{V}_{1}=e_{\psi} \dot{e}_{\psi}=e_{\psi}\left(r-\dot{\psi}_{d}\right)$

Select the virtual control law

$r=s_{\psi}-k_{1} e_{\psi}-\dot{\psi}_{d}$

From (28) and (29), the result of Step 1 becomes

$s_{\psi}=r+k_{1} e_{\psi}-\dot{\psi}_{d}$

$\dot{V}_{1}=-k_{1} e_{\psi}^{2}+e_{\psi} s_{\psi}$

Step 2:

Differentiating (30) with respect to time yields $\dot{s}_{\psi}=\dot{r}+k_{1} \dot{e}_{\psi}-\ddot{\psi}_{d}=a_{\dot{r}}(u, v, r)+b_{\dot{r}}+k_{1} \dot{e}_{\psi}-\ddot{\psi}_{d}$ Define the second CLF
$V_{2}=V_{1}+s_{\psi}^{2} / 2$

whose time derivative is

$\dot{V}_{2}=\dot{V}_{1}+s_{\psi} \dot{s}_{\psi}=-k_{1} e_{\psi}^{2}+s_{\psi}\left(e_{\psi}+\dot{s}_{\psi}\right)$

$=-k_{1} e_{\psi}^{2}+s_{\psi}\left(e_{\psi}+a_{\dot{r}}+b_{\dot{r} \tau_{3}}+k_{1} \dot{e}_{\psi}-\ddot{\psi}_{d}\right)$

Choose the control law

$\tau_{3}=\left[e_{\psi}+a_{\dot{r}+b_{r}} \tau_{3}+k_{1} \dot{e}_{\psi}-\ddot{\psi}_{d}-k_{2} s_{\psi}-\right.$

$\left.K_{s} \operatorname{sat}\left(s_{\psi}\right)\right] / b_{\dot{r}} \quad$ (32)

when the result of Step 2 is

$$
\begin{aligned}
& \dot{V}_{2}=-k_{1} e_{\psi}^{2}-k_{2} s_{\psi}^{2}-K_{s} \text { sat }\left(s_{\psi}\right) s_{\psi}<0 \\
& \text { We have } \dot{V}_{2}<0 \forall e_{\psi} \text { so } s_{\psi} \rightarrow 0 \text { and } e_{\psi} \rightarrow 0
\end{aligned}
$$

\section{RESULTS AND DISCUSSION}

This section presents simulation results of the combined system between guidance and control. To evaluate the results of the combined system, we will consider the simulation conditions in two cases with and without noise then bring them into comparison. Assume that the boundary value of measurement noise $M=0.5(\mathrm{~m})$ and the maximum allowed angular error is:

$$
P=\left\{\begin{array}{c}
2,\left|y_{e}\right| \leq M \\
5, M \leq\left|y_{e}\right| \leq 2.5 \text { (degrees) } \\
8,\left|y_{e}\right|>2.5
\end{array}\right.
$$

From (21) we can choose Delta noise:

$\triangle_{\text {noise }}=\left\{\begin{array}{c}20,\left|y_{e}\right| \leq M \\ e^{-\left(\left|y_{e}\right|-M\right)}, M \leq\left|y_{e}\right| \leq 2.5 \\ 8,\left|y_{e}\right|>2.5\end{array}\right.$

In all simulations, the desired surge velocity is chosen as $u_{d}=1 \mathrm{~m} / \mathrm{s}$ and the controller gain coefficients are chosen as $K_{u}=10, k_{1}=2, k_{2}=15, K_{s}=10$. The lookahead distances are selected in the common way are

Delta 1: $\Delta_{1}=3$

Delta 2: $\Delta_{2}=10$

Case 1: Without noise effect

Case 2: With noise effect

The results in two cases show that the combination of the controller and guidance is very effective, it helps the vessel converge and stay on the desired path. Figure 4 and Figure 8 show the guidance which has Delta noise will converge on the path faster than the other Delta. The speed assignment always satisfy through the result in Figure 6 and Figure 10.

Because the guidance with Delta noise converges on the path faster, it makes the trajectory longer and needs more time to finish. However, we can see the heading response from Figure 5 and Figure 9 where the heading response of Delta noise has the best quality.

In case 1, the moment control input shown in Figure 7 is possible in practice for all Delta. However, in Figure 11 of case 2, only the moment control input of 


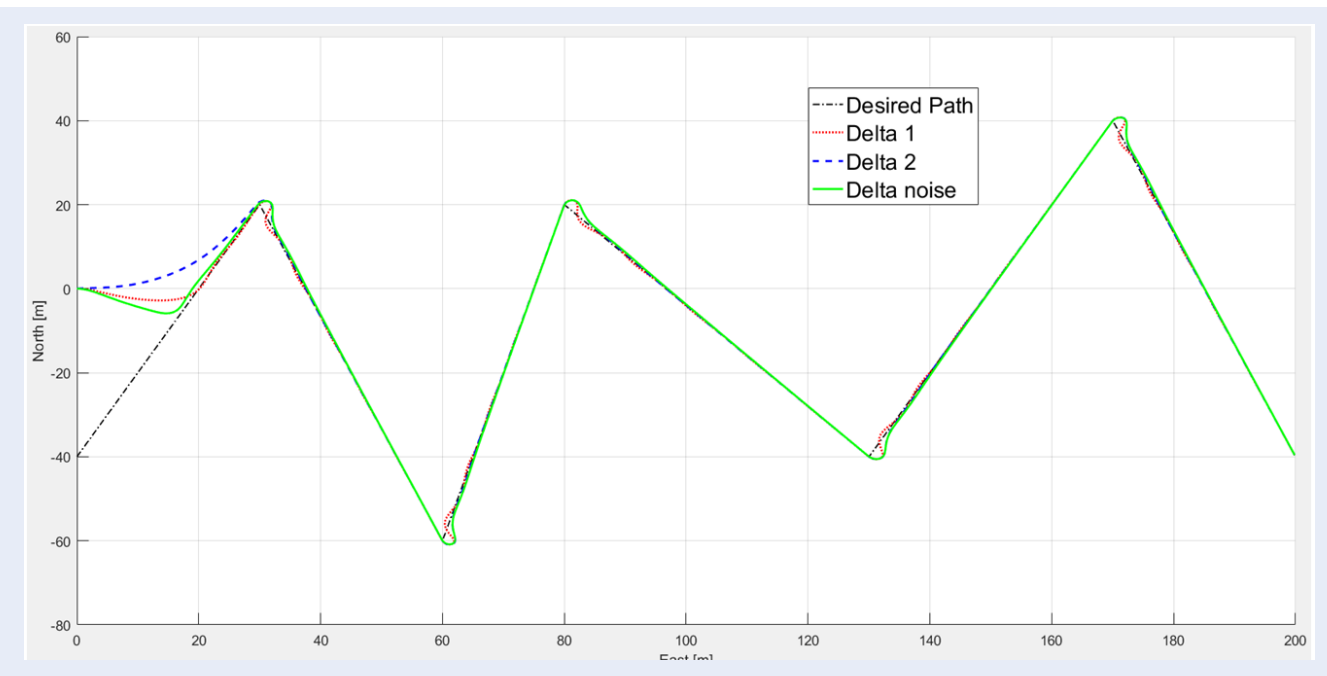

Figure 4: Desired and simulation path of Delta1 (black dash-dot and red dot, respectively), Delta 2 (blue dash) and Delta noise (green).

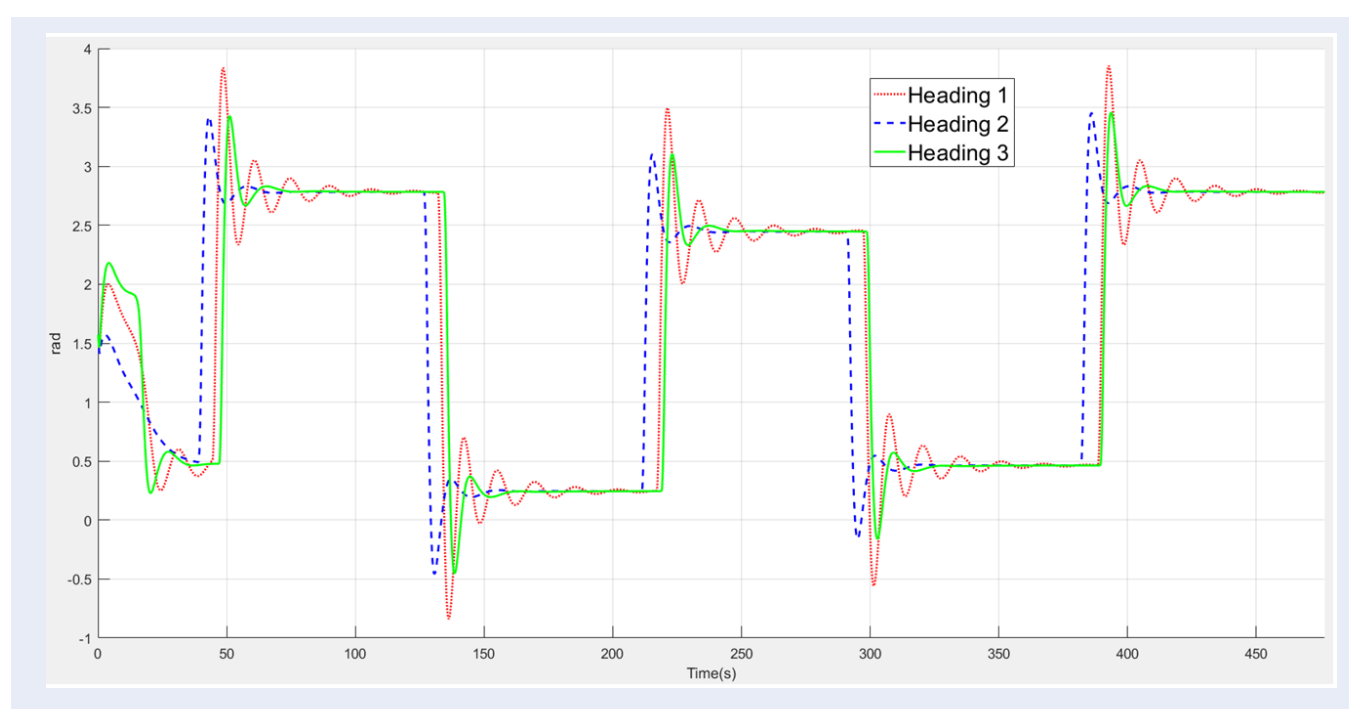

Figure 5: Heading responses relating to the selection ofthe lookahead distance listed as Delta 1, Delta 2 or Delta noise.

Delta 2 and Delta noise can apply in experiment and Delta noise has the best quality.

When the vessel reaches $\mathrm{wp}(k)$, the desired heading $\psi_{d}$ and cross-track error $\mathrm{y}_{e}$ will be recalculated according to the new waypoint $\mathrm{wp}(k+1)$. Hence, to evaluate the results of the selected Delta noise, we need consider the process from start to reach at the first waypoint or from $t=0$ to $t=42$. Through the result in Figure 12, the selected Delta noise has helped the system works very well and the maximum value of $\psi_{d}$ is less than 0.6 degrees and obviously satisfies the maximum allowed angular error $P$. Summary the proposed method to reduce the effect of position measurement noise on the quality control has been verified.

\section{CONCLUSION}

In this paper, a guidance and control system for unmanned surface vessels is developed to solve the control objective of making the vessel follow a desired path in the presence of measurement noise which effect to guidance and quality of heading controller.

Simulation results have demonstrated the effectiveness and feasibility of the proposed method. The combined system helps the vessel converge on the path 


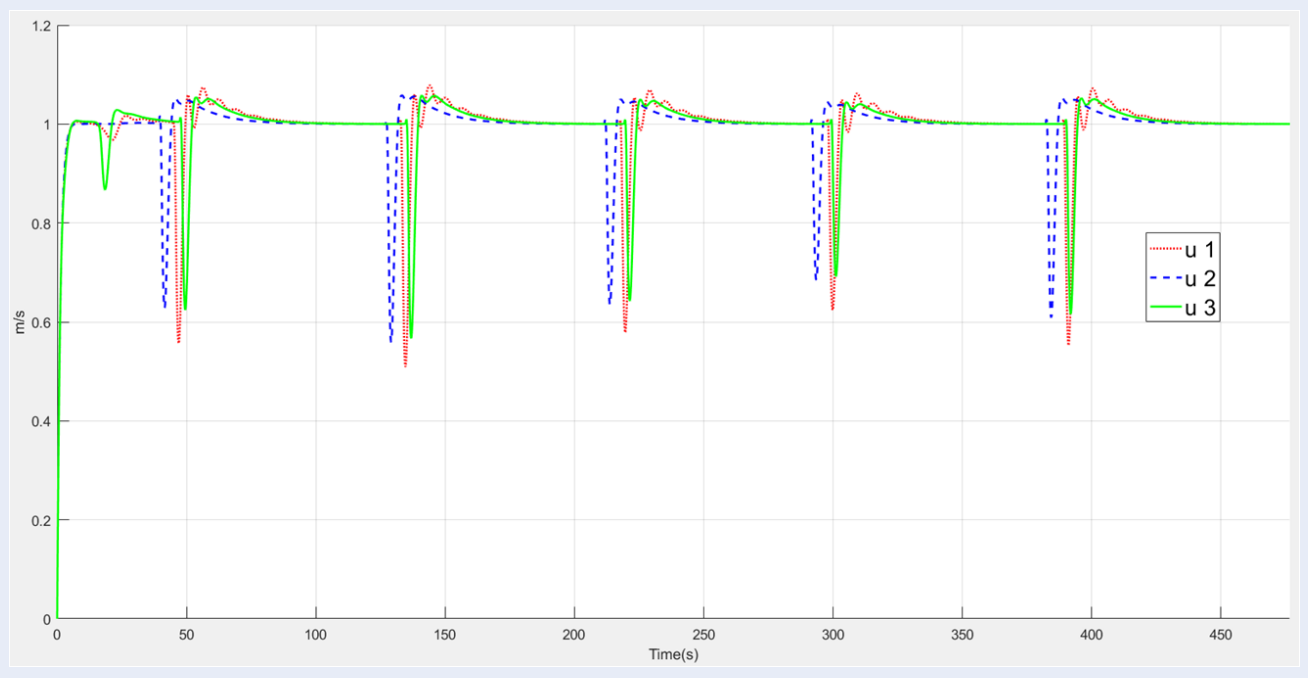

Figure 6: Surge velocity responses relating to theselection of the lookahead distance listed as Delta 1, Delta 2 or Delta noise.

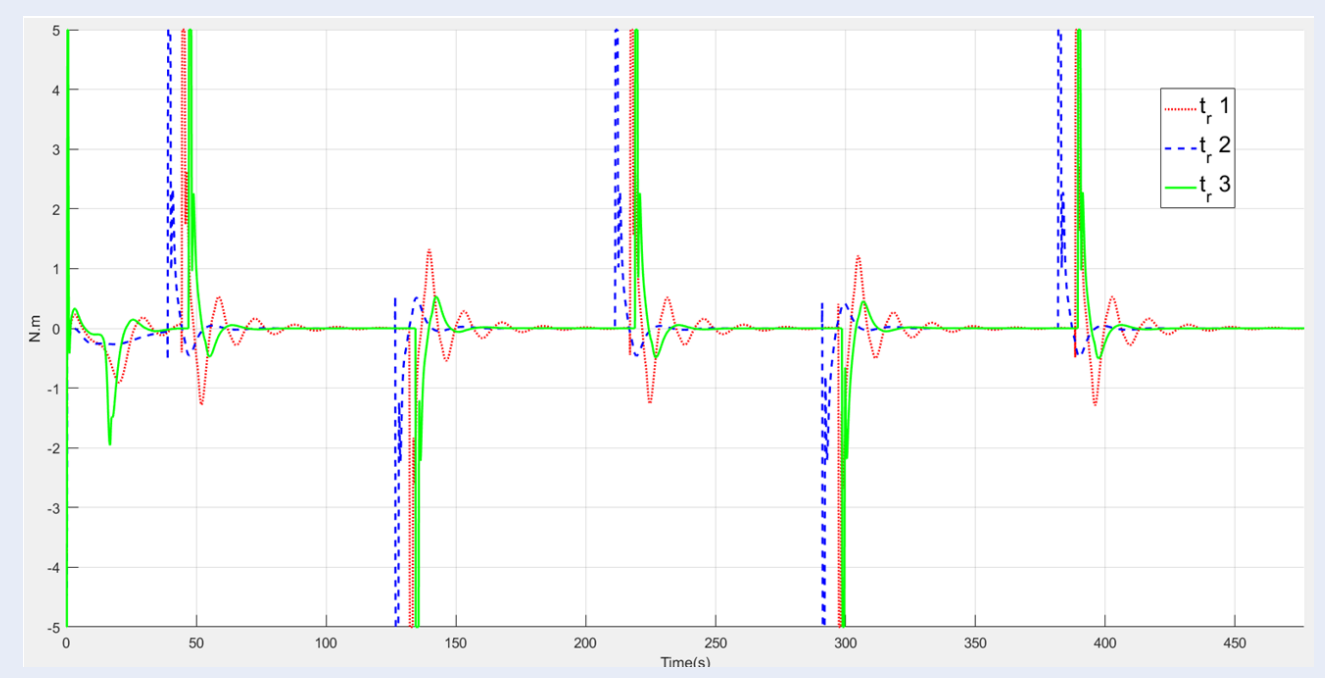

Figure 7: Moment control input relating to the selectionof the lookahead distance listed as Delta 1, Delta 2 or Delta noise.

and stay on it, besides that it still guarantee the speed assignment in case of measurement noise.

Further works focus on applying this method even for curve path and studying new control algorithm. Beside that it is possible to consider the effect of external disturbances on the system so that simulation results still ensure the quality when applied in practice.

\section{ACKNOWLEDGEMENT}

This research is supported by Laboratory of Advanced Design and Manufacturing Processes and funded by Ho Chi Minh City University of Technology, VNU-
HCM under grant number T-ĐĐT-2018-72.

\section{CONFLICT OF INTERESTS}

The author declares that this paper has no conflict of interests.

\section{AUTHORS' CONTRIBUTIONS}

Tran Ngoc Huy has developed the proposed algorithm and wrote the manuscript. Pham Nguyen Nhut Thanh implemented simulation and wrote the manuscript. 


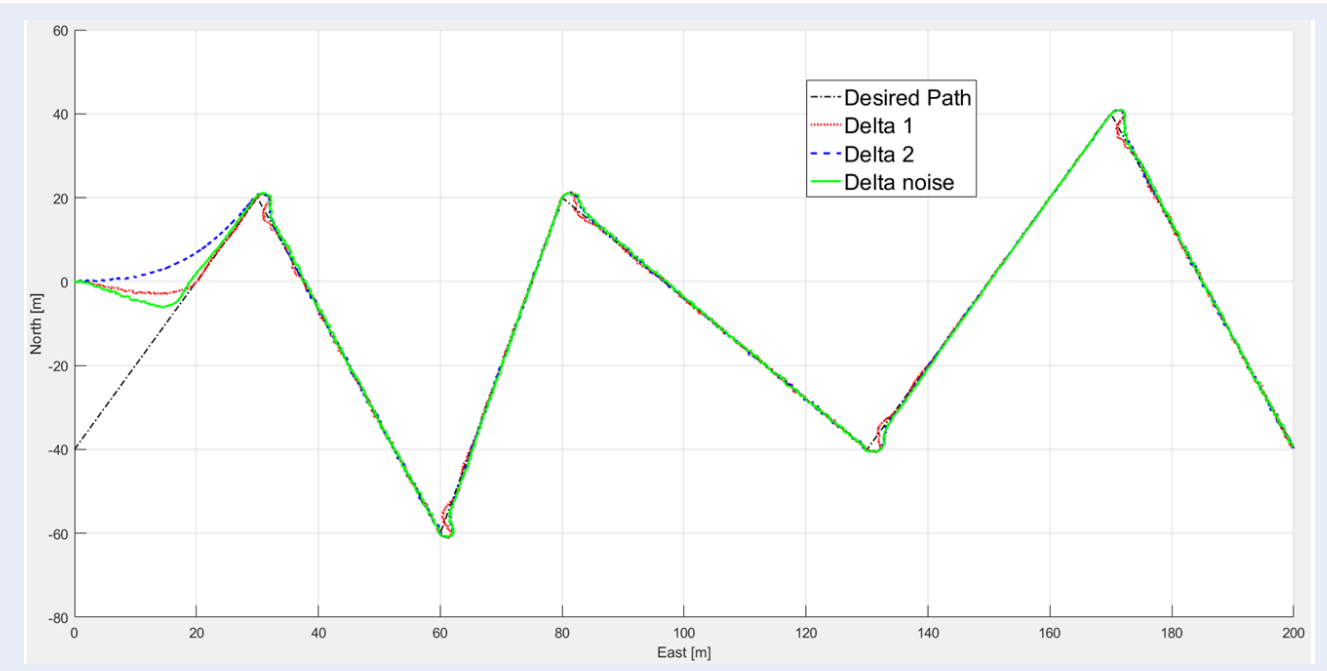

Figure 8: The trajectory of the vessel relating to theselection of the lookahead distance listed as Delta 1, Delta 2 or Delta noisewhen measurements have noise.

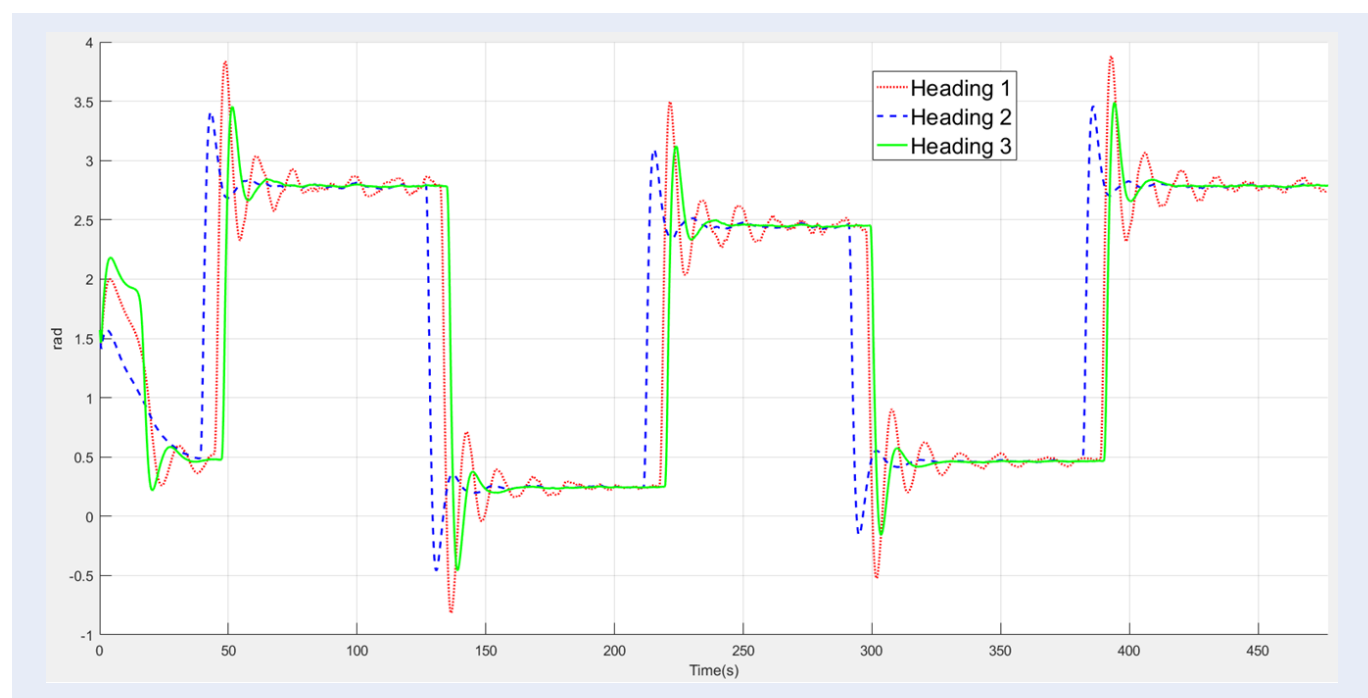

Figure 9: Heading responses relating to the selection ofthe lookahead distance listed as Delta 1, Delta 2 or Delta noise when measurementshave noise.

\section{ABBREVIATIONS}

LOS: Line of Sight

USV: Unmanned Surface Vessel

AUV: Autonomous Underwater Vehicle

ROV: Remotely Operated Vehicle

BSM: Backstepping Sliding Mode

CLF: Control Lyapunov Function

\section{REFERENCES}

1. Ferreira H, Almeida C, Martins A, Almeida J, Dias N, Dias A et al. Autonomous bathymetry for risk assessment with ROAZ robotic surface vehicle. OCEANS 2009-EUROPE. 2009;p. 16. Available from: https://doi.org/10.1109/OCEANSE.2009.
5278235.

2. Caccia M, Bibuli M, Bono R, Bruzzone G, Bruzzone G, Spirandelli E. Aluminum hull USV for coastal water and seafloor monitoring. OCEANS 2009-EUROPE. 2009;p. 1-5. Available from: https://doi.org/10.1109/OCEANSE.2009.5278309.

3. Tokekar $P$, Bhadauria $D$, Studenski A, Isler V. A robotic system for monitoring carp in Minnesota lakes. Journal of Field Robotics. 2010;27(6):779-789. Available from: https://doi.org/ 10.1002/rob.20364.

4. Ramos P, Cruz N, Matos A, Neves M, Pereira F. Monitoring an ocean outfall using an AUV," in MTS/IEEE Oceans 2001. An Ocean Odyssey. Conference Proceedings (IEEE Cat No01CH37295);3:2009-2014.

5. Fiorelli E, Leonard N, Bhatta P, Paley DA, Bachmayer R, Fratantoni DM. Multi-AUV Control and Adaptive Sampling in Monterey Bay. IEEE Journal of Oceanic Engineering. 


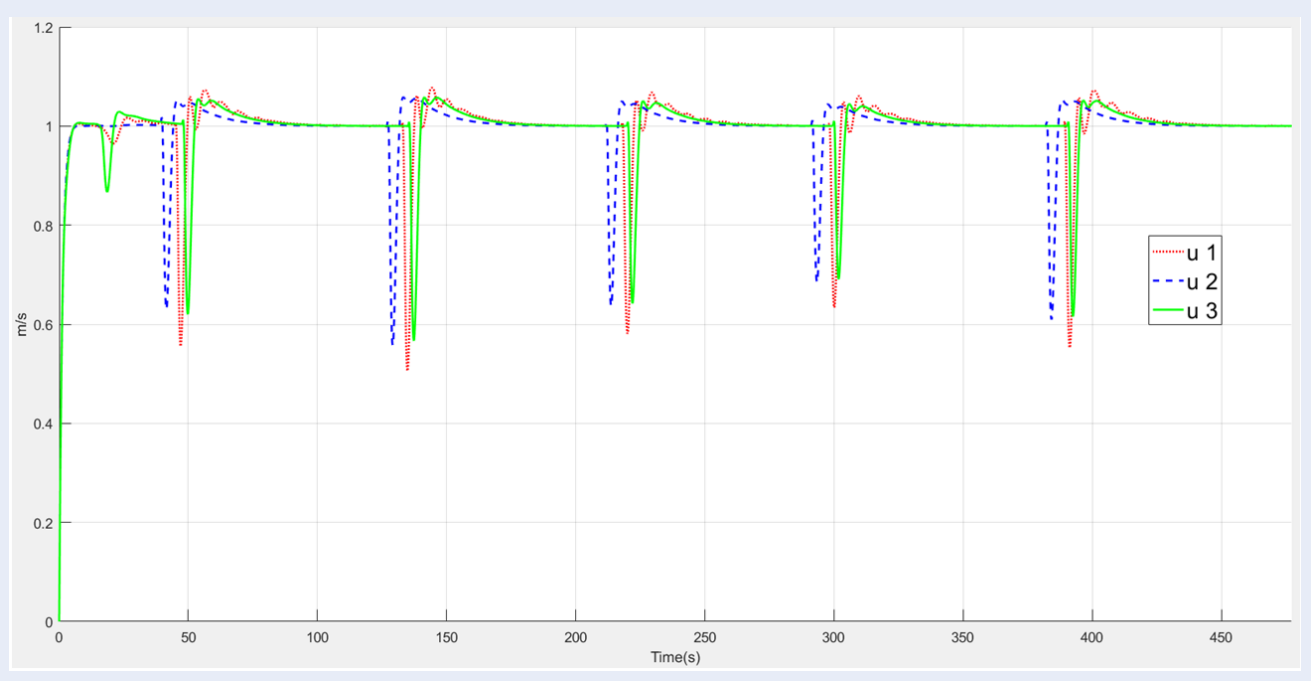

Figure 10: Surge velocity responses relating to theselection of the lookahead distance listed as Delta 1, Delta 2 or Delta noisewhen measurements have noise.

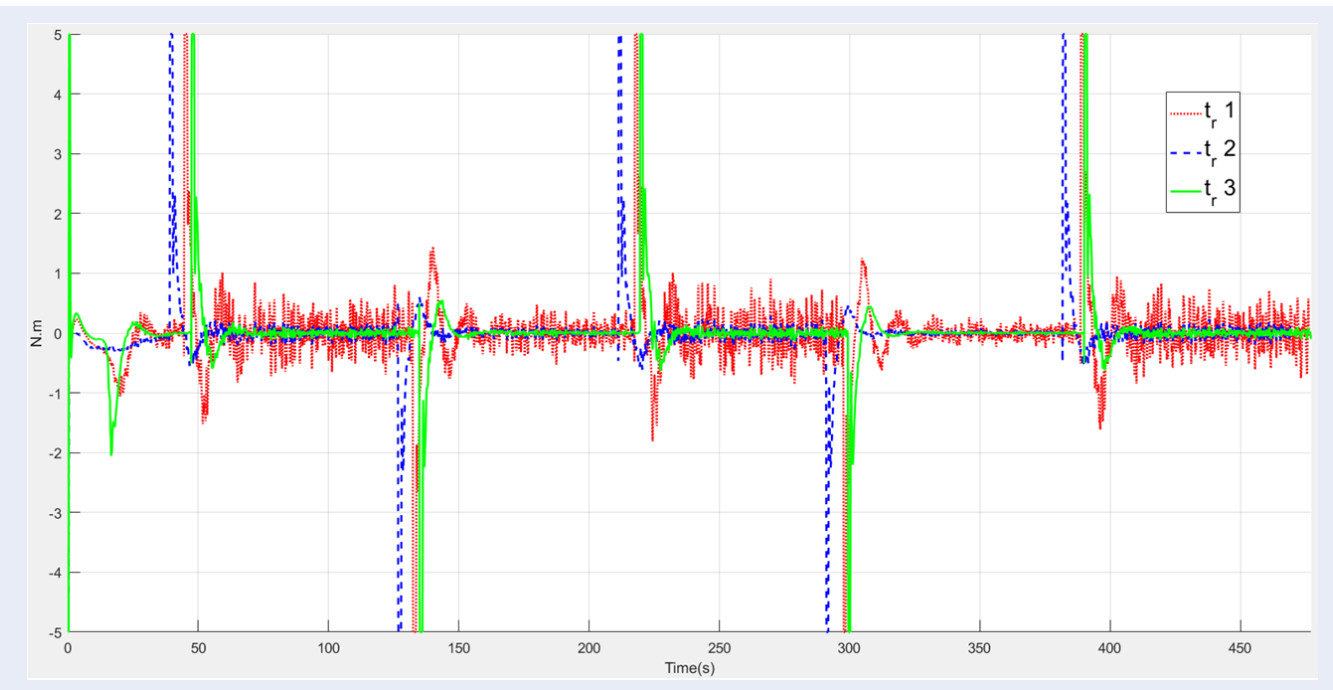

Figure 11: Moment control input relating to the selectionof the lookahead distance listed as Delta 1, Delta 2 or Delta noise when measurementshave noise.

2006;31(4):935-948. Available from: https://doi.org/10.1109/ JOE.2006.880429.

6. Kim A, Eustice R. Toward AUV Survey Design for Optimal Coverage and Localization Using the Cramer Rao Lower Bound. IEEE. 2009;.

7. Encarnacao P, Pascoal A. Combined trajectory tracking and path following: An application to the coordinated control of autonomous marine craft. Proceedings of the 40th IEEE Conference on Decision and Control. 2001;

8. Pettersen K. Way-point tracking control of ships. Proceedings of the 40th IEEE conference on decision \& control. IEEE, Orlando, FL, USA. 2001;p. 940-945.

9. Fossen T. Handbook of Marine Craft Hydrodynamics and Motion Control. Wiley. 2011;Available from: https://doi.org/10. 1002/9781119994138.
10. The Society of Naval Architects and Marine Engineers. Nomenclature for treating the motion of a submerged body through a fluid. Technical and Research Bulletin;(1-5).

11. Bai Y, Zhao Y, Li T. The USV path following controller design 2017 4th International Conference on Information, Cybernetics and Computational Social Systems (ICCSS). 2017;Available from: https://doi.org/10.1109/ICCSS.2017.8091500.

12. Yong L, Ren-Xiang B, Hai-Jun X. Straight-Path Tracking Control of Underactuated Ship Based on Backstepping Method. Ninth International Conference on Frontier of Computer Science and Technology. 2015;PMID: 25134927. Available from: https://doi.org/10.1109/FCST.2015.24.

13. Li M, Liu C, Li T, Chen CP. New second order sliding mode control design for course-keeping control of ship with input saturation. International Conference on Advanced Mechatronic Systems (ICAMechS). 2017;Available from: https://doi.org/10. 


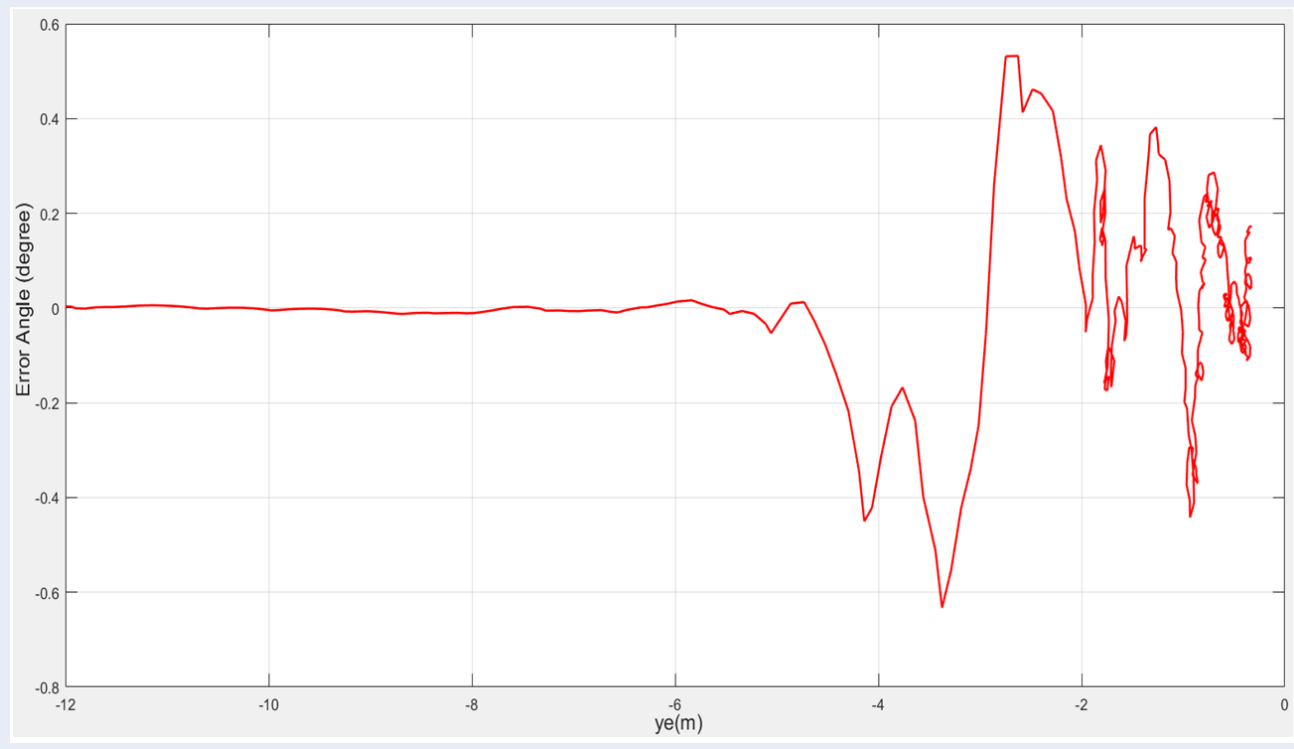

Figure 12: The angular error between the heading angle withnoise and without noise related to cross-track error $\mathbf{y}_{e}$ from $\mathrm{t}=\mathbf{0}$ to $\mathrm{t}=\mathbf{4 2}(\mathrm{s})$.

1109/ICAMechS.2017.8316518. 


\section{Bám đường cho phương tiện tàu tự hành dưới sự ảnh hưởng của nhiễu đo lường vị trí}

Trần Ngọc Huy*, Phạm Nguyễn Nhựt Thanh

Trường Đai học Bách Khoa,

ĐHQG-HCM

\section{Liên hệ}

Trần Ngọc Huy, Trường Đại học Bách Khoa, ĐHQG-HCM

Email: tnhuy@hcmut.edu.vn

Lịch sử

- Ngày nhận: 15-10-2018

- Ngày chấp nhận: 19-12-2018

- Ngày đăng: 13-12-2019

DOI : 10.32508/stdjet.v3iSI1.721

\section{Check for updates}

\section{Bản quyền}

๑ ĐHQG Tp.HCM. Đây là bài báo công bố mở được phát hành theo các điều khoản của the Creative Commons Attribution 4.0 International license.

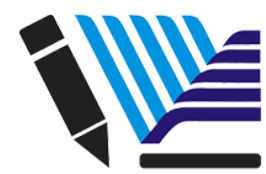

VNU-HCM Press

\section{TÓM TÁT}

Một hệ thống vân hành cho tàu không người lái trên măt nước (USV) nói chung cũng như các phương tiện khồng người lái và tàu tự hành nói riêng thường được xây dựng bởi ba thành phần chính là hệ thống dẫn đường, hệ thống định vị và hệ thống điều khiển. Trong đó bộ định vị sẽ dùng các cảm biến để đo đạc và ước lược các thông số để cung cấp các giá trị đâuu vào cho bộ dẫn đường và bộ điều khiển. Dựa trên các dữ liệu nhận được từ bộ định vị và các chỉ tiêu mà người dùng đề ra, bô dẫn đường sẽ tính toán và xuất dữ liệu tham chiếu đầu vào cho bộ điều khiển. Bộ điều khiển sẽ lái phương tiện theo các dữ liệu tham chiếu được cung cấp từ bộ dẩn đường để đạt được các chỉ tiêu đã để ra. Tuy nhiên, trong thực tế việc đo đạc và ước lượng thường bị ảnh hưởng bởi nhiễu gây ra sai số đầu vào cho bộ dẫn đường. Điều này dẫn đến dữ liệu mà bộ dẫn đường tính toán sẽ có sai lệch và gây rối loạn bộ điều khiển, từ đó làm giảm chất lượng điều khiển cũng như có thể dẫn đến mất ổn đinh cho toàn hê thống. Trong bài viết này ta sẽ xét bài toán điều khiển một tàu không người lái trên mặt nước bám theo quỹ đạo thẳng do các điểm waypoint cho trước tạo thành. Để giải quyết bài toán bám đường thẳng này, bài viết sẽ sử dụng phương pháp Line of sight (LOS) để thiết kế bộ dẫn đường và giải thuật Backstepping sliding mode cho việc xây dựng bộ điều khiển. Đồng thời nghiên cứu, phân tích và đề xuất một phương pháp nhằm giảm ảnh hưởng của nhiễu đo lường đến quá trình tính toán giá trị tham chiếu của bộ dẫn đường. Từ đó chất lượng của hệ thống đã xây dựng sẽ được đảm bảo khi hoạt động dưới tác động của nhiễu đo lường. Kết quả cũng quả của phương pháp để xuất sẽ được trình bày qua mô phỏng trên phần mềm MATLAB/SIMULINK. Các kết quả này sẽ minh chứng cho tính hiệu quả và khả thi của phương pháp đề xuất.

Từ khoá: Thuyền tự hành, Điều khiển bám quỹ đạo, Line of sight (LOS), Điều khiển trượt, Điều khiển cuốn chiếu
Trích dẫn bài báo này: Huy $\mathrm{T} \mathrm{N}$, Thanh $\mathrm{P} \mathrm{N} \mathrm{N}$. Bám đường cho phương tiện tàu tự hành dưới sự ảnh hưởng của nhiễu đo lường vị trí. Sci. Tech. Dev. J. - Eng. Tech.; 2(SI1):SI38-SI48. 